\title{
ELECTROPLATING OF THIN FILMS OF MAGNETIC Fe-Ni ALLOYS
}

S.N. SRIMATHI and S.M. MAYANNA

Department of Chemistry, Central College, Bangalore University Bangalore- 560001 (India).

Received 29 February 1984; accepted 3 April 1984

\section{ABSTRACT}

Electroplating of thin films of Fe-livi alloys from an acidic sulphate bath containing thioglycollic acid (IGA) and mercaptoethanol (MET) has been studied under different plating conditions. The composition of the alloy is altered with the plating variables. The cathodic current efficiency (CCE) is found to depend on current density, teinperature and $\mathrm{pH}$ of the medium. The cathodic potential drifted towards less noble direction with increase of current density, temperature and concentration of the addition agent. TGA is a more effective addition agent than MET. The deposited alloy with higher nickel content is smooth and bright with small grain size and uniform solid solution. Electroplating conditions were optimised to get 20:80 Fe:Ni magnetic alloys with the required magnetic property.

\section{INTROLUCTION}

Electroplated Fe-Ni alloys find extensive applications in microelectronic [1] and metal finishing [2,3] industries. The Fe-Ni systeril shows a set of exceptional possibilities: no structural transformation above $30 \%$, low anisotropy and low magnetostriction for special composition. Fe-Ni alloys with a wide range of specific desirable magnetic properties can be produced by adjusting plating variables [4]. In recent years there has been a greater emphasis on bath solutions containing lower concentrations of electrolytes with a low working temperature. Recently the electroplating of binary magnetic alloys has been reviewed [5] . Thin magnetic films of 20:80 Fe-Ni alloys have been electroplated from acid and alkaline complex baths by using pulse current [6] . 
direct current [7] and superimposing alternating current on direct current[8-10] . Sulphur compounds have been used as metal brightners [11] and to increase the anodic and cathodic efficiencies [12] - As part of a broad procramme of work on electroplating of magnetic binary alloys, we report here electroplating of Fe-Ni alloys from an acidic sulphate bath containing addition agents such as thioglycolic acid (TGA) and mercaptoethanol (MET).

\section{EXPERIWENTAL}

The solutions were prepared by using distilled water and Reagent gracie chemicals. Experiments were carried out at $30^{\circ} \mathrm{C}$ and $\mathrm{pH} 4.8$ under unstirred conditions to a constant thickness. The molar ratio of $\mathrm{Fe} / \mathrm{Ni}$ in the bath solution was $30 / 70$. The bath solution had the composition: $\mathrm{NiSO}_{4} 0.0525 \mathrm{~N}, \mathrm{FeSO}_{4} 0.0225 \mathrm{M}$, ascorbic acid $0.006 \mathrm{M}$, boric acid $20 \mathrm{gm} / \mathrm{L}$ and addition agent $0.03 \mathrm{M}$.

Freshly prepared copper-plated platinum foil $(2 \mathrm{~cm} \times 2 \mathrm{~cm})$ and cylindrical platinum foil were used as cathode and auxiliary electrode, respectively. Deposition potentials were recorded with reference to the saturated Calomel electrode using a systronics digital multimeter (Nodel - 435). The surface morphology of the deposit was examined with a metallurgical microscope. The $X$-ray diffraction analysis of the alloy was carried out by the powder method. After each experiment, the alloy was stripped in $\mathrm{HNO}_{3}$ solution $(1: 4)$ and composition of the alloy was obtained by atomic absorption spectrochemical analysis. The complex nature of the bath solution was examined by visible, UV and IR spectral analysis.

\section{RESULTS}

\section{Effect of olating variables}

Experiments were carried out to study the effect of plating variables such as current density (cd), $\mathrm{pH}$, temperature, bath composition and stirring of the medium. In all these experiments, the $\mathrm{pH}$ was maintained constant using boric acid. Ascorbic acid was added to the bath solution to reduce $F e$ (III) to $F e(I I)$, if any, and there by preventing the precipitation and subsequent incorporation of ferric hydroxide into the deposit.

The Fe-Ni alloy was electroplated to a constant thickness $(0.4 \mathrm{~mm})$ at a constant cd of $0.5 \mathrm{~A} \mathrm{dm}^{-2}$ from the bath solutions containing various molar ratios of $\mathrm{Fe} / \mathrm{Ni}(40 / 60$ to $5 / 95)$ with a $\mathrm{pH} 4.8$ and 
working temperature $30^{\circ} \mathrm{C}$. The percentage values of $\mathrm{Ni}$ in the deposit at various bath compositions are given in Table 1.

Table I. Effect of Bath Composition on the Composition of Fe- $\mathrm{Ni}$ Alloys with and without Addition Agents.

\begin{tabular}{clll}
\hline $\begin{array}{c}\text { Bath composition } \\
(\% \mathrm{Ni})\end{array}$ & \multicolumn{4}{c}{$\% \mathrm{Ni}$ in the deposit } \\
\cline { 2 - 4 } & None & \multicolumn{1}{c}{$\mathrm{TGA}$} & \multicolumn{1}{c}{ MET } \\
\hline 60 & 49 & 83.8 & 64.0 \\
70 & 52 & $90.9(88.6)$ & $75.8(62.5)$ \\
80 & 61 & 95 & 83 \\
90 & 75 & 97.2 & 94.0 \\
95 & 82 & 98.5 & 97.0 \\
\hline
\end{tabular}

* Boric acid $20 \mathrm{gm} / \mathrm{h}$, ascorbic agid $0.006 \mathrm{~N}$, TGA or MET $0.03 \mathrm{~h}$, $\mathrm{pH} 4.8$, Temp. $30^{\circ} \mathrm{C}$, cda5A $\mathrm{dm}^{-2}$, thickness $0.4 \mu \mathrm{m}$.

The values of the percentage of $\mathrm{Ni}$ in the deposit under stirred conditions are given in parenthesis.

In the absence of addition agents, the percentage of $\mathrm{Fe}$ in the deposit was more than in the bath solution. However, the situation was quite different in the presence of addition agents. Each bath solution containing an addition agent with a higher percentage of Fe was found to give the alloy containing a lower percentage of $\mathrm{Fe}$. Under identical plating conditions and concentration of addition agent, the extent of the increase of $\mathrm{Ni}$ in the deposit was more with TGA than with MET.

Experiments were also carried out at different cd values $\left(0.1-2 \mathrm{~A} \cdot \mathrm{dm}^{-2}\right)$ using a bath solution containing a constant molar ratio of $\mathrm{Fe} / \mathrm{Ni}(30 / 70)$ and $0.03 \mathrm{M}$ addition agent at $30^{\circ} \mathrm{C}$. The percentage of $\mathrm{Ni}$ in the deposit, electroplated from the bath solution containing TGA or MET, decreased gradually and then attained a constant value with increase of cd (Fig.1). In the presence of MET, the compositions of the alloy varied significantly with cd. However, the effect of cd on the percentage of $\mathrm{Ni}$ in the deposit was not much in the presence of TGA.

$\mathrm{pH}$ and temperature are considered to be the important plating variables during plating of metals and alloys. Hence, to find the influence of $\mathrm{pH}$ and temperature on the composition of the Fe-Ni alloy, the alloy was electroplated at different $\mathrm{pH}$ values (2-6) and temperatures $\left(30-50^{\circ} \mathrm{C}\right)$. The percentage of $\mathrm{NI}$ in the deposit decreased with increase of $\mathrm{pH}$ of the bath solution containing a known 


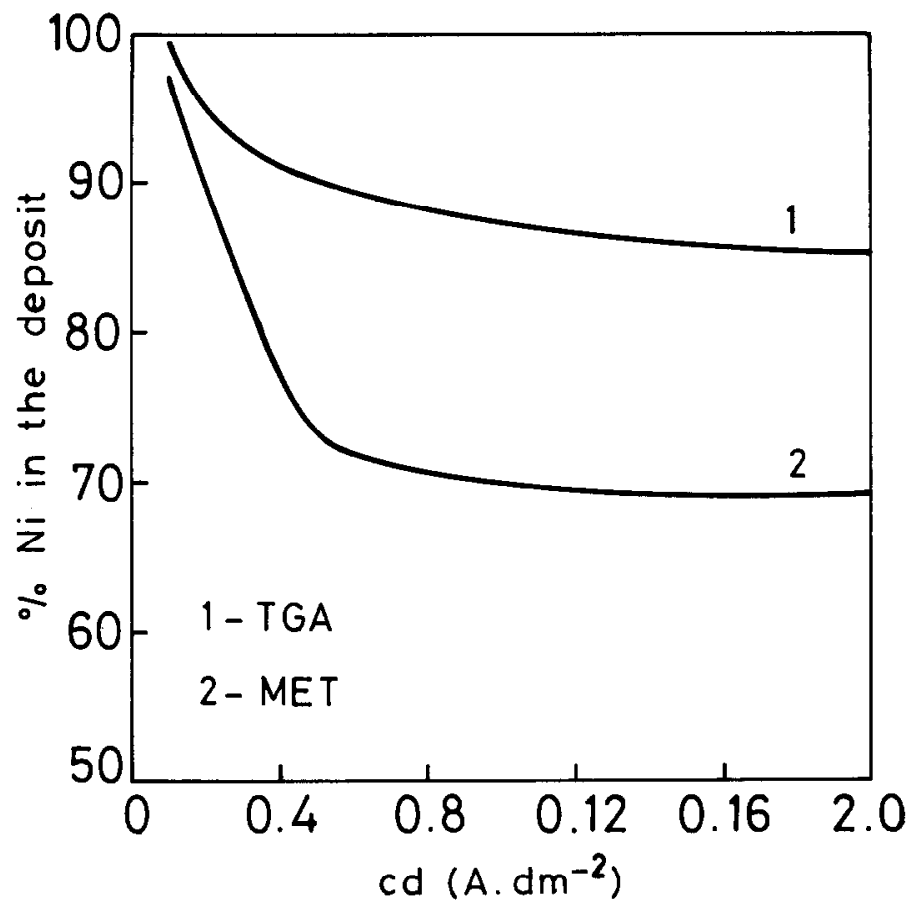

Fig.1. Effect of current density on percentage of $\mathrm{Ni}$ in the deposit at $30^{\circ} \mathrm{C}$ and $\mathrm{pH} 4.8$, thickness $0.4 \mu \mathrm{m}, \mathrm{NiSO}_{4} 0.0525 \mathrm{M}, \mathrm{FeSO}_{4}$ $0.0225 \mathrm{M}$, ascorbic acid $0.006 \mathrm{M}$, boric acid $20 \mathrm{~g} / 1$, TGA or MET $0.03 \mathrm{M}$.

concentration (0.03M) of MET (Table 2). An increase in temperature enhanced the percentage of $\mathrm{Ni}$ in the veposit (Table 2). Similar effects of temperature and $\mathrm{pH}$ on the composition of the alloy were observed in the presence of TGA.

Table 2. Dependence of the Composition of the Alloy on Temperature and $\mathrm{pH}$.

\begin{tabular}{|c|c|c|c|c|c|c|c|}
\hline \multirow{2}{*}{$\begin{array}{l}\text { Addition } \\
\text { agent }\end{array}$} & \multicolumn{4}{|l|}{$\mathrm{pH}^{*}$} & \multicolumn{3}{|c|}{ Temperature ${ }^{+}$} \\
\hline & 炭 $\mathrm{Ni}$ & in the & depos & & & & \\
\hline & 2.0 & 3.0 & 4.8 & 6.0 & $30^{\circ} \mathrm{C}$ & $40^{\circ} \mathrm{C}$ & $50^{\circ} \mathrm{C}$ \\
\hline TGA & 96.7 & 93.7 & 90.9 & 82.1 & 90.9 & 91.0 & 92.7 \\
\hline MẼT & 99.0 & 92.5 & 75.8 & 60.0 & 75.8 & 86.0 & 98.7 \\
\hline
\end{tabular}

* Temperature $30^{\circ} \mathrm{C},+\mathrm{pH} 4.8$. Bath composition: $\mathrm{NiSO}_{4} 0.0525 \mathrm{M}$, $\mathrm{FeSO}_{4} 0.0225 \mathrm{M}$, ascorbic acid $0.006 \mathrm{M}$, TGA or MET $0.03 \mathrm{M}$, thickness $0.4 \mu \mathrm{m}, c \mathrm{clo} .5 \mathrm{~A} \mathrm{dm}^{-2}$. 
Uncier a set of plating conditions such as: bath composition $(\mathrm{Fe} / \mathrm{Ni}-30 / 70), \mathrm{cd}\left(0.5 \mathrm{~A} \mathrm{dm}{ }^{-2}\right), \mathrm{pH}(4.8)$ and temperature $\left(30^{\circ} \mathrm{C}\right)$, alloys were el ctroplated in the presence of various concentrations (0.0.15\%) of TGA and NET. Fig.2 illustrates the dependence of

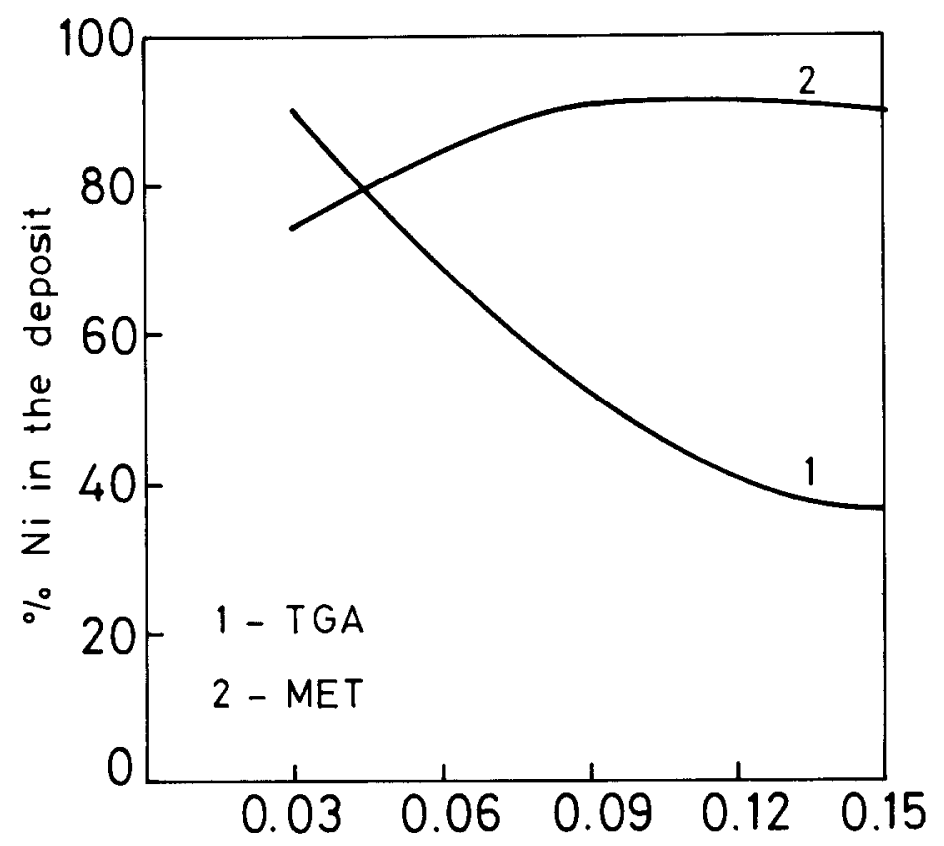

Sulphur compound $(M)$

Fig.2. Dependence of percentage of $\mathrm{Ni}$ in the deposit on addition agent concentration at $30^{\circ} \mathrm{C}$ and $\mathrm{pH} 4.8$, thickness $0.4 \mathrm{~mm}$. $\mathrm{NiSO}_{4} 0.0525 \mathrm{li}, \mathrm{FeSO}_{4} 0.8225 \mathrm{liv}$, ascorbic acid $0.006 \mathrm{li}$, boric acid $20 \mathrm{~g} / 1$, cd $0.5 \mathrm{~A}^{4} \mathrm{dm}^{-2}$.

percentage of $\mathrm{Ni}$ in the deposit on the concentration of addition agent. The anount of $\mathrm{Ni}$ in the deposit increased slightly and attained a limiting value with an increase in KET concentration. However, in the presence of TGA the percentage of $\mathrm{Ni}$ decreased continuously with an increase in concentration of TGA.

To investigate the effect of thickness on the composition of the alloy, experiments were performed to various values of thickness $(0.1-0.5 \mu \mathrm{m})$ at constant $\mathrm{cd}\left(0.5 \mathrm{~A} \mathrm{dm}^{-2}\right)$, temperature $\left(30^{\circ} \mathrm{C}\right)$, and $\mathrm{pH}$ (4.8). Fig. 3 shows the variation of the percentage of $\mathrm{Ni}$ with the thickness of the deposit. The composition of the alloy deposited from a bath solution containing IGA was constant throughout $i$ ts thickness. In the presence of liET the percentage of $\mathrm{Ni}$ in the 


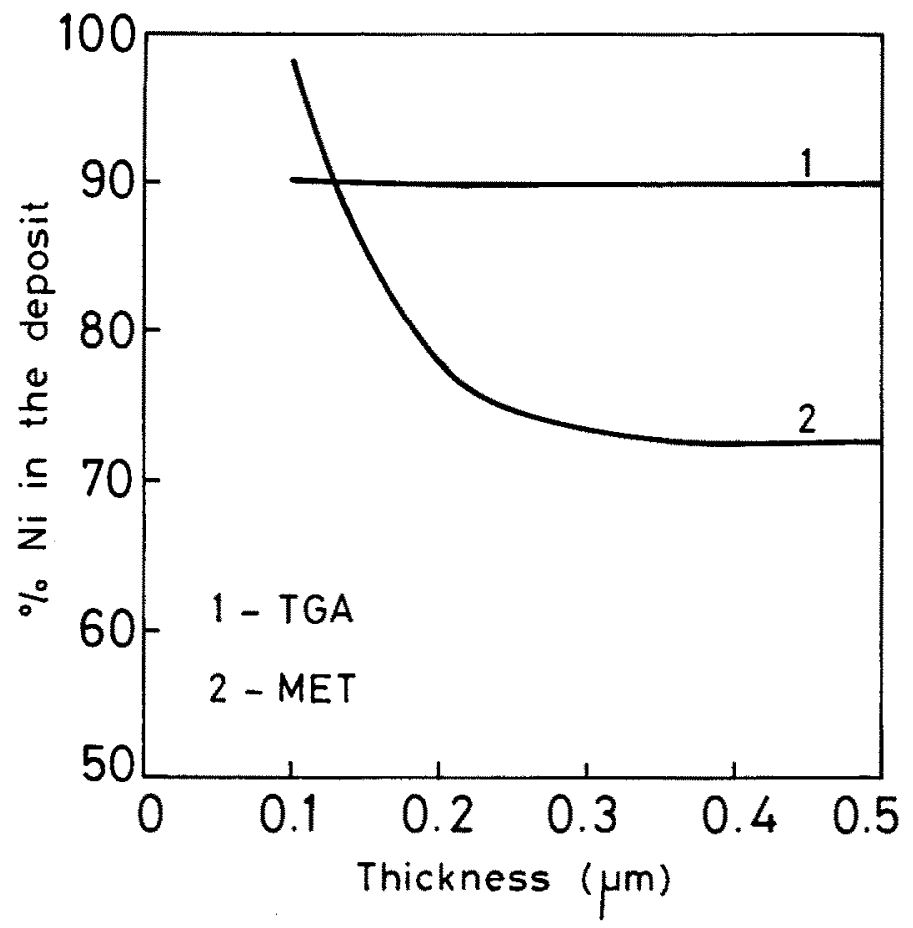

Fig.3. Variation of percentage of $\mathrm{Ni}$ in the deposit with thickness at $30^{\circ} \mathrm{C}$ and $\mathrm{pH} 4.8, \mathrm{Ni}_{4} 0.0525 \mathrm{M}, \mathrm{FeSO}_{4} 0.025 \mathrm{M}$, ascorbic acid $0.006 \mathrm{M}$, boric acid $20 \mathrm{~g} / 1$, cd $0.5 \mathrm{~A} \mathrm{dm}^{-2}$.

deposit decreased initially and attained a limiting value with an increase of thickness.

In order to know the part played by diffusion during electroplating of Fe-Ni alloys, some experiments were carried out under stirred conditions. At a given cd, temperature, bath composition and concentration of addition agent, agitation of the solution did not affect the composition of the alloy much (Table 1.). Agitation of the mediun decreased the percentage of $\mathrm{Ni}$ slightly, both in the presence of TGA and liET.

\section{Deposition potential}

Deposition potentials were recorded at different time intervals during ceposition of Fe-Ni alloys under various plating varlables. The deposition potential in the absence and presence of addition agents slightly decreased with time and attained a steady value. The steady deposition potential was a function of the $\mathrm{Fe} / \mathrm{Ni}$ ratio 
in the bath solution, temperatu-c, p-i, cd and the nature and concentration of the a:iition agent. Fig. 4 illustrates the

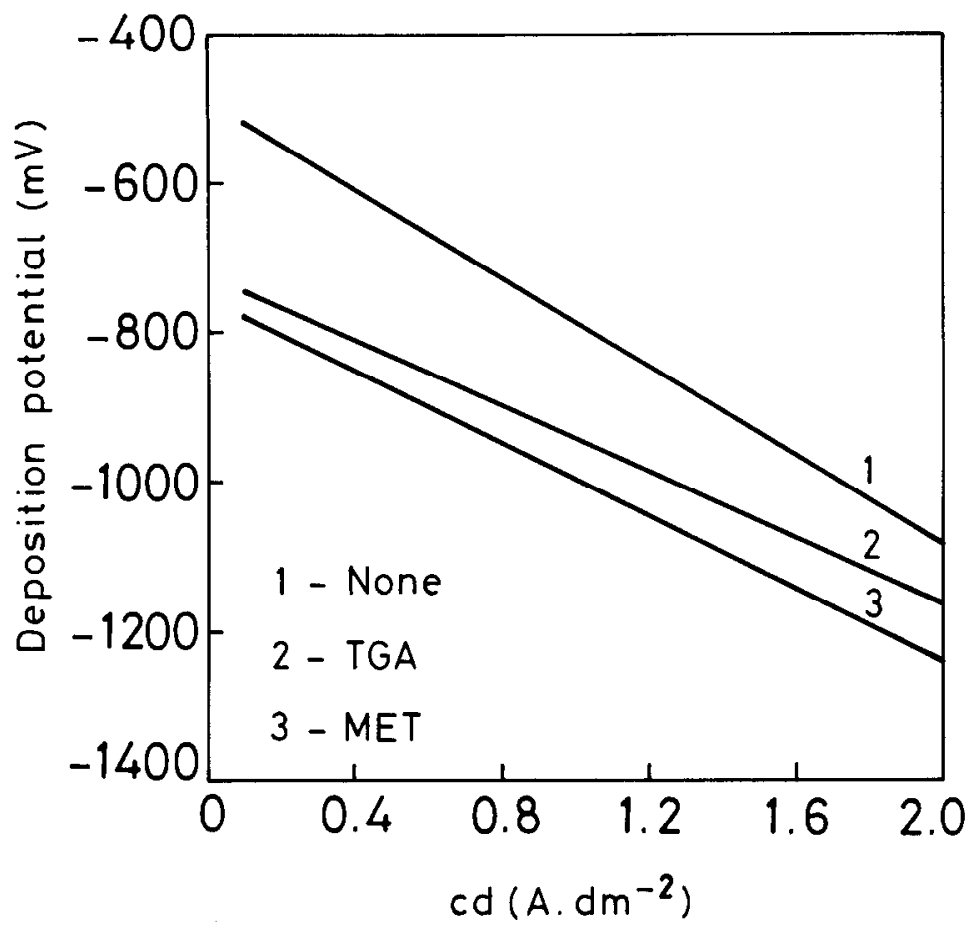

Fig. 4. Jeposition potential as a function of current density at $30^{\circ} \mathrm{C}$ pii 4.8 , thickness $0.4 \mathrm{um}$. $\mathrm{NiSO}_{4} 0.0525 \mathrm{~K}$, FeSU $0.0225 \mathrm{~K}$, a scorbic acid $0.006 \mathrm{i}$, boric acid $20 \mathrm{~g} / 1$, TGA lli. $0.03 \mathrm{~m}$.

variation of steady deposition potential with $\mathrm{cd}$ with and without $0.03 \mathrm{w}$ acidition agent at $30^{\circ} \mathrm{C}$ and $\mathrm{pH} 4.8$. At each cd, the steady cieposition potertial in the absence of addition agent $\left(V_{0}\right)$ drifted towards a less noble direction in the presence of adidition a ents. Uncier identical plating conditions, the steary devosition potentials ace in the order $V_{0}>V_{T G \hat{i}}>V_{\text {live }}$.

\section{Cathodic cur $r$ nt efficiency}

The values of cathodic curr nt efficiency (CCE) were calculated under differnt plating concitions. CCE was found to ciepend on bath solution, $\mathrm{pH}$, terperature and the concentration of addition acent. The values of $C D E$ at roresentative plating variables are given in Table 3. At a given $c d$ and concentration of addition acgent, the percentage Cue increased with an increase in pH or terperature; actition of the medium decreased the percentage Cus consicerably. 
Table 3. Cathodic Current Efficiency

\begin{tabular}{lll}
\hline $\begin{array}{c}\text { Current density } \\
\left(A \mathrm{dm}^{-2}\right)\end{array}$ & \multicolumn{3}{c}{ Cathodic current efficiency (\%) } \\
\cline { 2 - 3 } & TGA & NET \\
\hline 1.0 & 98.5 & 65.0 \\
5.0 & $97.2(64.5)$ & $77.8(67.6)$ \\
$5.0^{*}$ & 81.0 & 62.9 \\
$5.0^{+}$ & 100.0 & 90.1 \\
$5.0^{*}$ & 54.8 & 64.9 \\
\hline
\end{tabular}

Bath composition and operating conditions as in Table 2.

* jtirring, + at $50^{\circ} \mathrm{C}$, * TGA or MET 0.15ly. Values at pH 3 are given in parenthesis.

A decrease in the percentage CCE was noticed either with an increase in cd or with an increase in concentration of addition agent (at constant $c d$ ). Under identical experimental conditions, the percentage CCE in the presence of TGA was slightly greater than in thie presence of MET.

\section{Surface morohology}

After each experiment, the surface morphology of the Fe-Ni alloy was examined under a metallurgical microscope. The Fe-Ni alloy deposited from the bath solution free from addition agent was dull and had a rough structure. In the presence of an addition agent, under a certain range of $\mathrm{pH}$ and temperature, the alloy deposit a peared bright, fine grained and uniform when the $\mathrm{Ni}$ content of the deposit was above $70 \%$ (Fig. 5A). The grain size of the deposit increased gradually with an increase in temperature or thickness of the deposit or a decrease in cd. The alloys with a high percentage of Fe appeared spongy and dull. After heat treatment of the alloy deposits in a vaccum electric furnace at $500^{\circ} \mathrm{C}$ for two hours, the deposits from the addition agent free bath did not change appreciably, but grain growth was observed (Fig.5B) in the deposit from the bath solution containing an addition agent.

\section{SCUSSION}

Electroplating of Feni alloys from simple salt baths exhibits [13] anomalous co-deposition, $F e$, being the less noble metal, deposits in preference to the more noble metal $\mathrm{Ni}$. $\mathrm{H}_{2}$ evolution during plating brings about a rise in local pH around the cathode which favours the formation, precipitation and deposition of 

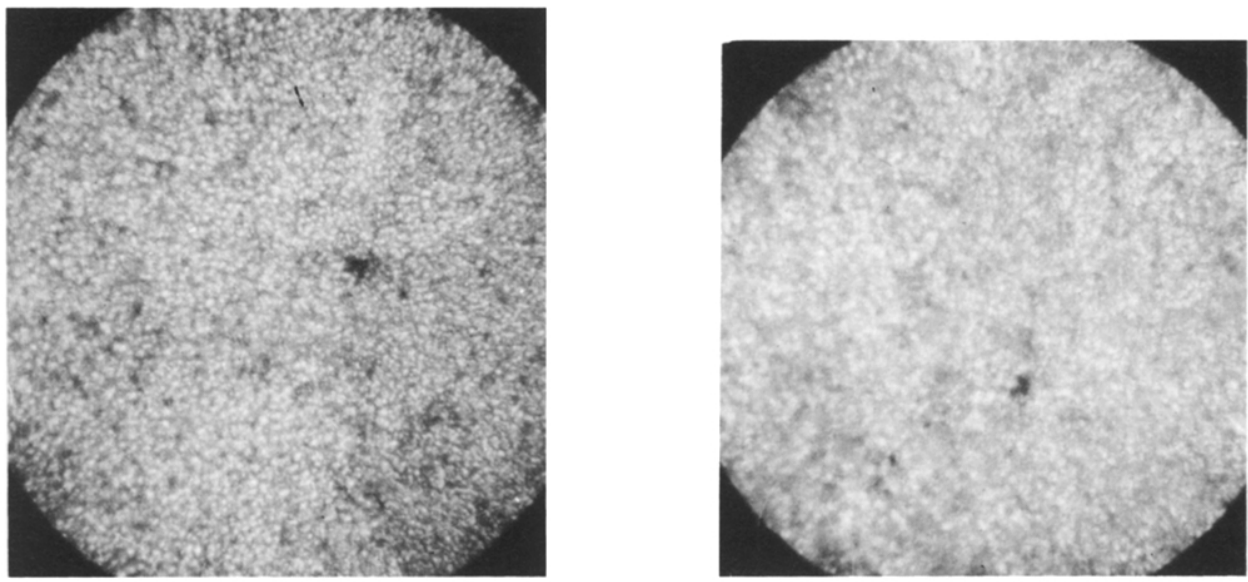

Fig.5. A. Photomicrograph of $\mathrm{Fe}-\mathrm{Ni}$ alloy $(\times 600)$ deposits from the bath solution: $\mathrm{NiSO}_{4} 0.0525 \mathrm{~N}, \mathrm{FeSO}_{4} 0.0225 \mathrm{l}$, ascorbic acid $0.006 \mathrm{~W}$, boric acid $20 \mathrm{~g} / 1$, IGA $0.03 \mathrm{~h}$, cd $0.5 \mathrm{~A} \mathrm{dm}-2$, temp. $30 \circ \mathrm{C}$, thickness $0.4 \mathrm{\mu m}, \mathrm{pH} 4.8$. B. Heat treatment $\left(5000^{\circ}, 2 \mathrm{~h}\right)$.

$\mathrm{Fe}(\mathrm{OH})_{2}$ or $\mathrm{Fe}(\mathrm{OH})_{3}$ and retards the rate of discharge of $\mathrm{Ni}$ (II) ions. Some addition agents [14] and sultable buffers [15] are used to avoid the precipitation of these hydroxides and a pH rise in the electroplating baths.

The present electroplating system in the absence of addition agents show the characteristics of anomalous co-deposition (Table 1) which is decreased considerably by the presence of addition agents. The study of the effect of addition agent on alloy plating is very complex. The varied nature of the effects of addition agents makes it improbable that they can all be explained by one single action. From the typical bath solutions, complexes were isolated and were subjected to $U V$, visible and IR spectral analysis. The mercaptide ion exhibited an intense band in the uv region which shifted to the larger wave length on complexation. The IR spectra of both $\mathrm{Fe}$ and $\mathrm{Ni}$ complexes showed the absence of SH stretching frequency and shifting of the $C=0$ stretching frequency. Even the visible absorption spectra (Fig.6) showed the complexation of both Fe (II) and $N$ (II) ions with TGA and MET. Some of these spectral data aie in accordance with the earlier spectral reports [16-18] on the complexes of $\mathrm{Fe}$ and $\mathrm{Ni}$ with TGA and MET. 


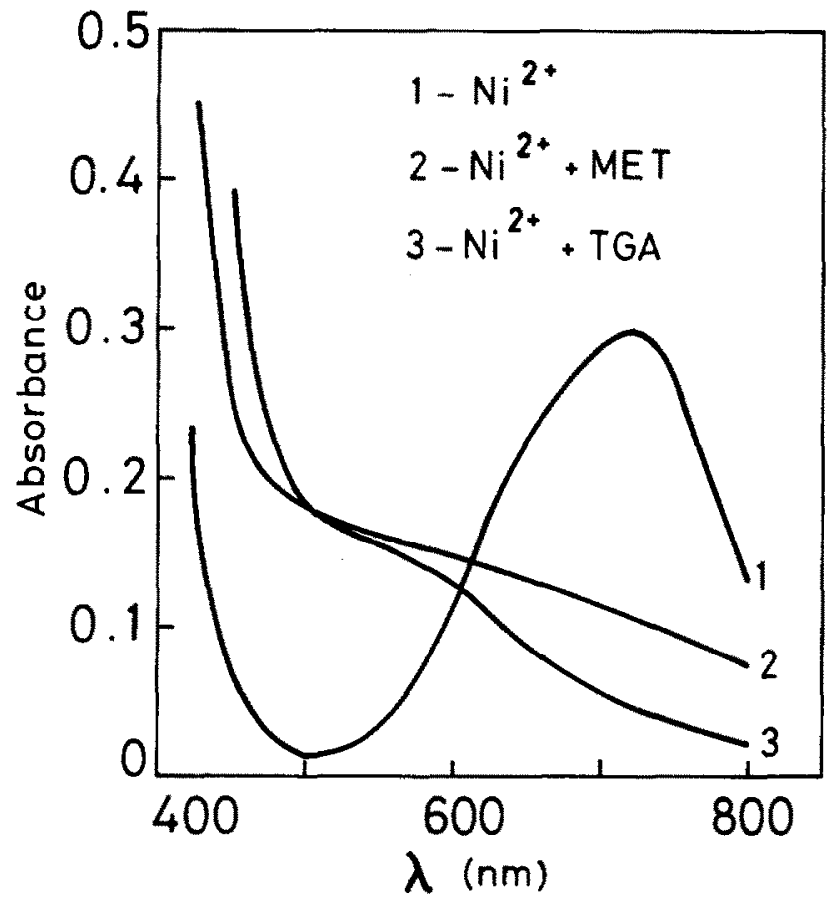

Fig. 6. Absorption spectra of Ni-TCA system and Ni-MET system ( $\mathrm{pH} \mathrm{4.8)}$ (1) $\mathrm{NiSO}_{4} 0.15 \mathrm{k}$, boric acid $20 \mathrm{~g} / 1$, ascorbic acid $0.006 \mathrm{M}$. (2) $\mathrm{NiSO}_{4} 40.0525 \mathrm{M}$, MET $0.03 \mathrm{M}$, boric acid $20 \mathrm{~g} / \mathrm{h}$, ascorbic acid $0.006 \mathrm{M}$. (3) $\mathrm{NiSO}_{4} 0.0065 \mathrm{M}$, TCA $0.03 \mathrm{M}$, boric acid $20 \mathrm{~g} / \mathrm{L}$, ascorbic acid $0.006 \mathrm{~N}$.

It is known that compounds containing as $\mathrm{SH}$ group lower the cathodic polarization and stimulate electrochemical discharge reactions by preventing hydrogen ion (or atom) adsorption $[19,20]$. Experimental results in the presence of an addition agent shows: (i) lowering of plating potential at a given cd, and (ii) enhancement of the percentage of $\mathrm{Ni}$ in the deposit. This confirms the preferential adsorption and discharge of $\mathrm{Ni}$ complexes on the cathode [21]. This brings about the concentration polarization (considerable decrease of concentration of $\mathrm{Ni}$ (II) ions and increase of concentration of complexing agent at the cathode diffusion layer), which depends on the $\mathrm{pH}$ of the medium, the nature and concentration of the complexing agent, the stability of the complex and the cd. During co-deposition of two metals, it is unlikely that each metal would experience the same extent of concentration polarization. 
The trend in variation of composition of $\mathrm{Fe}-\mathrm{Ni}$ alloy with cd mostly depends on the rance of cd used, thetype of bath solution (complexing or not) anithe nature of the discharge step (activation or diffusion controlled) at the catho.e. An increase in co suppressed the $\mathrm{Ni}$ content in the deposit (Fig.1), because Ni deposition is uncier diffusion control. At high: $r$ values of $c d$, the $F e$ content in the alloy deposit remained constant because of the co-deposition of an isoluble iron compound. Some of these results are in accordance with the gen ral rule [22] in alloy plating that an increase in cd tends to increase the proportion of the less noble metal in the alloy deposition.

The depencience of the composition of the alloy with thickness is usually related to the c ncentration - time profile of metallic ions across the cathodic diffusion layer. In the presence of TCA, constant composition of the alloy across thickness (Fig. 3 ) is due to the rapid decrease and attainment of a steady $\mathrm{Ni}$ (II) ion concentration at the cathode diffusion layer. However, a similar situation occurs in the presence of MET only after a short time lag. A slight increase of the amount of $\mathrm{Fe}$ in the deposit by agitation of the bath solution (Table 1) indicates that the plating system is of the diffusion-controlled anomalous type.

The effect of temperature on the composition of the alloy (Table 2) could be explained by taking into account the influence of polarization and diffusion. On raising the temperature, there may be a reduction in the polarization during $\mathrm{Ni}$ discharge which subsequently enhances the rate of deposition of $\mathrm{Ni}$. It is known that an increase in temperature increases the cathode current efficiency of a preferentially depositing metal complex [23]. Hence, an increase in temperature increases the amount of $\mathrm{Ni}$ in the deposit. The complexing agent in an electroplating bath always favours the deposition of a metal by forming a cathodically active complex with the metal ions. The lowering of $\mathrm{pH}$ may activate the $\mathrm{Ni}$ complex suitably to discharge at a faster rate at the cathode which finally enhances the $\mathrm{Ni}$ content in the deposit (Table 2). The decrease in current efficiency at higher cd values and at lower $\mathrm{pH}$ values or with stirring of the medium (Table 3 ) may be due to the increase of rate of evolution of $\mathrm{H}_{2}$ during alloy plating.

The measured values of coercivity of a few typical Fe-Ni alloys (Table 4) were found to vary with $\mathrm{pH}$, temperature, cd, bath composition, concentration of the addition agent and thickness of the 
Table 4. Magnetic Properties of 20:80 Fe-Ni Alloys

\begin{tabular}{|c|c|c|c|}
\hline \multirow{2}{*}{\multicolumn{2}{|c|}{$\begin{array}{l}\text { Bath solution } \\
\text { with plating conditions }\end{array}$}} & \multicolumn{2}{|c|}{ Coercivity } \\
\hline & & Unheated & Heated \\
\hline 1. & $\begin{array}{l}\mathrm{NiSO}_{4} 0.0525 \mathrm{k}, \mathrm{FeSO}_{4} 0.0225 \mathrm{M} \\
\mathrm{TGA} 0.03 \mathrm{k}, \mathrm{pH} 6 \text {, cd } 0.5 \mathrm{~A} \mathrm{dm}-2 \\
\text { temp. } 30^{\circ} \mathrm{C} \text {, thickness } \\
0.4 \mu \mathrm{m} .\end{array}$ & 2 & $2.1\left(2.2^{+}\right)\left(0.8^{*}\right)\left(4.9^{\xi}\right)$ \\
\hline 2. & $\begin{array}{l}\mathrm{NiSO}_{4} 0.0525 \mathrm{M}, \mathrm{FeSO}_{4} \\
0.0225 \mathrm{M}, \mathrm{TGA} 0.04 \mathrm{M}, \mathrm{pH} 4.8, \\
\text { cd } 0.5 \mathrm{Adm}^{-2}, \text { temp. } 300 \mathrm{C} \\
\text { thickness } 0.4 \mu \mathrm{m} .\end{array}$ & 13.0 & 1.9 \\
\hline 3 & $\begin{array}{l}\mathrm{NiSO}_{4} 0.0525 \mathrm{M}, \mathrm{FeSO}_{4} \\
0.0225 \mathrm{M} \mathrm{NET} 0.03 \mathrm{M}, \mathrm{pH} 4.8, \\
\text { cd } 0.35 \mathrm{~A} \mathrm{dm}^{-2} \text {, temp. } 30 \circ \mathrm{C} \text {, } \\
\text { thickness } 0.4 \mu \mathrm{m} .\end{array}$ & 9.5 & $2.4\left(0.4^{*}\right)(5.8 *)\left(0.6^{5}\right)$ \\
\hline
\end{tabular}

* Ascorbic acid $0.006 \mathrm{~N}$, boric acid $20 \mathrm{~g} / \mathrm{l}_{\mathrm{f}}$

+ At $0.1 \mu \mathrm{m},{ }^{*} \mathrm{pH} 4.8$ (with MET pH 6), "TGA or NET $0.06 \mathrm{M}$.

deposit. On the basis of the present work one could optimise the experimental conditions (Table 5) to get thin films of 20:80 Fe-Ni magnetic alloys.

Table 5. Optimum Experimental Conditions to Electroplate $80: 20$ $\mathrm{Ni}-\mathrm{Fe}$ Alloys at $30^{\circ} \mathrm{C}$ to a Thic kness of $0.4 \mu \mathrm{m}$.

\begin{tabular}{|c|c|c|c|}
\hline $\begin{array}{l}\text { Addition } \\
\text { agent }\end{array}$ & Bath Solution & $\mathrm{pH}$ & $\operatorname{cd}\left(A \cdot d m^{-2}\right)$ \\
\hline \multirow[t]{2}{*}{ TGA } & $\begin{array}{l}\mathrm{NiSO}_{4} 0.0525 \mathrm{ki}, \mathrm{FeSO}_{4} 0.0225 \mathrm{in} \\
\mathrm{TGA}\end{array}$ & 4.8 & 0.5 \\
\hline & $\begin{array}{l}\mathrm{NiSO}_{4} 0.0525 \mathrm{li}, \mathrm{FeSO}_{4} 0.0225 \mathrm{M} \\
\mathrm{TGA} 0.03 \mathrm{M}\end{array}$ & 6.0 & 0.5 \\
\hline \multirow[t]{2}{*}{$M E T$} & $\begin{array}{l}\mathrm{NiSO}_{4} 0.0525 \mathrm{M}, \mathrm{FeSO}_{4} 0.0225 \mathrm{M} \\
\mathrm{MET} 0.03 \mathrm{M}\end{array}$ & 4.8 & 0.35 \\
\hline & $\begin{array}{l}\mathrm{NiSO}_{4} \quad 0.0525 \mathrm{~h}, \mathrm{FeSO}_{4} 0.0225 \mathrm{M} \\
\mathrm{MET} 0.05 \mathrm{M}\end{array}$ & 4.8 & 0.5 \\
\hline
\end{tabular}

* boric acid $20 \mathrm{~g} / 1$, ascorbic acid $0.006 \mathrm{~N}$.

ACKNOWLEDGENENTS

The authors aie grateful to Prof. G.K.N. Reddy, Head of Dept. of Chemistry, Central College, Bangalore for laboratory facilities and the authorities of Central Laboratories, Geological Survey of 
India, Eanalore for atomic absorption facilities. One of the authors (S.N.S.) expresses her gratitude to Dr. K.F. Dambal, III, Bangalore for providing magnetic property measuring facilities. REFERENCES

1 J.S. Sallo, Plating, 54,(1967) 257.

2 R.A. Tremmel, Elatino and jurface Finishing, 68, (1981) 22.

3 B. Sunanda, M.jc., Dissertation, Bangalore Univ. India, 1983.

4 H.D. Richard, J. Humpage and J.C. Hendy, IEEE Irans Hac: WG-4, (1968) 351 .

5 S.N. Srimathi, S.i. Wiayanna and B.3. Sheshadri, Surface Technology, 16, (1982) 277.

6 H.V. Venkata Setty, J. Electrochemical Soc., 117, (1970) 403.

7 S.N. Srimathi and S.i.. Mayanna, J.Appl. Electrochemistry 13, (1983) 679 .

8 Zlata Kovac, J. Electrochemical Soc. 118, (1971) 51.

9 S.N. Srimathi, B.3. Sheshadri and S.l..hiayanna, Surface Iechnolooy, 17, (1982) 217.

10 B.S. Sheshadri, V. Koppa, B.S. Jaiprakash and S. W. Wiayanna, Surface Technolocy, 13 (1981) 111.

11 J.H. Haslam, Us pat, 2230, 112 (d. 204-4T) March 1, 1966 (Chem. Abst. 64, No.10, hiay 1966).

12 T.B. Such and A. Poloniurz Wysynski, Brit. Pat. 920, 922, Warch 13, 1963 (Chem.Abst. 59, No.1, July 1963).

13 A. Brenner, Electrodeposition of Alloys, Vol. I. Academic Press, New York, 1963, p.77, 84.

14 P.s. Titov and M.V. Korovin, lating, 46 (1959) 262.

$15 \mathrm{~J}$. Harkons, J. Electrochemical Soc. 126, (1978). 1861.

16 D.L. Leussing, R.E. Laramy and G.S. Alberts, J.Am, Chem. Soc. $82(1960) 4826$.

17 L.B. Orgel, Quart. Rev. 8 (1954) 422.

18 R.0.Gould and R.i.. Taylor, Chem. and Ind. 2 (1966) 378.

19 W. Wesley, Irans, Inst. het. Finishing, 33, (1956) 452.

20 S.C. Barns, J. Electrochemical Soc. III, (1964) 296. 
21 L.L. Shreir and J.W. Smith, Irans. Faraday joc. 50, (i954) 393.

22 F.A. Lowenheim, iocern Electroplating, 3rd Edn. iiley New York, 1974, p. 501.

23 j. Feild, Trans. Faraday Soc, 6, (1910)1

24 D.L. Leussing and I.... Kolthoff, J. Am. Ghem. joc. 75(1953) 3904 . 